\title{
Vibrio alginolyticus
}

National Cancer Institute

\section{Source}

National Cancer Institute. Vibrio alginolyticus. NCI Thesaurus. Code C86840.

A species of facultatively anaerobic, Gram negative, curved rod shaped bacteria assigned to the phylum Proteobacteria. This species is motile, oxidase positive, hemolytic,

halophilic, can utilize a wide variety of sug ars as carbon sources and is responsible for the production of tetrodotoxin in puffer fish. V. alginolyticus is a marine organism and a pathogen that can cause otitis and wound infections in humans. 